\title{
Expression of microRNA-132 in patient with liver cancer and mediation of microRNA-132 on cell growth of liver cancer cell
}

\author{
Li-Wei Liu', Li-Xin Zhu² and Bo Liu3 \\ ${ }^{1}$ Department of Biotherapy, The $105^{\text {th }}$ Hospital of People's Liberation Army, Hefei Anhui 230 061, China; \\ ${ }^{2}$ Central Lab, The First Hospital of Anhui Medical University, Hefei Anhui 230 061, China; ${ }^{3}$ Department of \\ Infection Disease, The 105 $5^{\text {th }}$ Hospital of People's Liberation Army, Hefei Anhui 230 061, China.
}

\begin{tabular}{|c|c|}
\hline \multicolumn{2}{|l|}{ Article Info } \\
\hline $\begin{array}{l}\text { Received: } \\
\text { Accepted: } \\
\text { Available Online: }\end{array}$ & $\begin{array}{r}4 \text { June } 2015 \\
9 \text { August } 2015 \\
26 \text { August } 2015\end{array}$ \\
\hline \multicolumn{2}{|c|}{ DOI: 10.3329/bjp.v10i3.23572 } \\
\hline \multicolumn{2}{|c|}{$\begin{array}{l}\text { Cite this article: } \\
\text { Liu LW, Zhu LX, Liu B. Expression of } \\
\text { microRNA-132 in patient with liver } \\
\text { cancer and mediation of microRNA- } \\
132 \text { on cell growth of liver cancer cell. } \\
\text { Bangladesh J Pharmacol. 2015; } 10: 726 \\
-31 \text {. }\end{array}$} \\
\hline
\end{tabular}

\begin{abstract}
We detected the expression of microRNA-132 in Chinese patient with liver cancer and evaluated down-regulation of microRNA-132 affect on cell growth and apoptotic of liver cancer cell. Twenty four patients with liver cancer and 24 normal patients were obtained from the 105th hospital of People's Liberation Army. We measured the expression of microRNA-132 in all selected patients using quantitative RTPCR (qRT-PCR). Lastly, cell growth and apoptotic of liver cancer Human liver cancer MHCC97H cells after antimicroRNA-132 transfection were evaluated using CCK-8 solution and annexin V-FITC and propidium iodide kit. There was significant suppression in microRNA-132 expression of exosome and whose liver cancer cell, comparison with normal patients. Down-regulation of microRNA-132 could inhibit cell growth and activated apoptotic of liver cancer cell. These findings indicate that microRNA-132 provides increased sensitivity of detection than normal patients. MicroRNA-132 may serve as a potential biomarker for treatment on liver cancer.
\end{abstract}

\section{Introduction}

Liver cancer is one of most common cancers (Wolosz et al., 2014). Every year, about 64 thousands of people all over the world are initially diagnosed with liver cancer, among which more than half are Chinese (Zhang et al., 2014b). In China, the leading cause of liver cancer's remarkable rise lies in the evolution of liver cirrhosis after infection of HBV (Allam et al., 2010). Data on 1990s showed that fatality rates of liver cancer are ranked the second (Tang, 2001). Liver cancer is progressing fast and its attack is concealed (Outwater, 2010). Consequently, intra-hepatic or extra-hepatic metastasis has occurred for most patients at initial diagnosis, thus they lost chances to receive radical treatment (Behe et al., 2003). For a few patients, disease can be found at early stage and diagnosis as well as treatment can be conducted, thus they can live longer (Xie et al., 2015).
Pharmacogenetics is a subject studying effects of genetic polymorphism on drug reaction (GonzalezVacarezza et al., 2013). In view of functional genomics and molecular pharmacology, pharmacogenomics is developed on the basis of pharmacogenetics at the end of 1990s and is an achievement of implementation of HGP (Vasku et al., 2009). Its main focus is to study pharmacogenetics by using results of genomics ( $\mathrm{Li}$ et al., 2013). More specifically, it is to study the hereditary basis of polymorphism of drug reactions, to prove and explain modes of action as well as toxic and adverse effects of drug therapeutic effects and actions from the perspective of molecular level, which provides a platform to develop new drugs and guide rational drug use (Lam et al., 2013). Therefore, security and effectiveness of drug use are increased and adverse reactions are avoided. Meanwhile, costs and risks of drug therapy decrease (Kim et al., 2013). 
MicroRNA is a non-coding single stranded RNA with a length of about 22 nucleotides, which is formed by Dicer enzyme-processing of precursors of single stranded RNA in cell nucleus and cytoplasm. It was recognized early in 1993 (Zhang et al., 2014a). It is single structured and participates in essential biological functions such as cell development, apoptosis and metabolism, etc (Wang et al., 2013). As the important role of microRNA in some tumors has been confirmed, many scholars conducted initial studies on relationship between microRNA and occurrence, development and metastasis of liver cancer (Toffanin et al., 2011; Wang et al., 2014). Results showed that microRNA was closely related with liver cancer.

\section{Materials and Methods}

\section{Participants}

Twenty four patients with liver cancer and 24 patients other than liver cancer were obtained from the $105^{\text {th }}$ Hospital of People's Liberation Army. Blood samples of all patients were gathered and stored at $-80^{\circ} \mathrm{C}$ for analysis. The tumor type and the grade of liver cancer were diagnosed based on the criteria of World Health Organization (WHO) and International Union Against Cancer (UICC) TNM classification.

\section{Serum samples}

Firstly, peripheral blood from all participants was gathered and centrifuged at 2,000 rpm for $10 \mathrm{~min}$ at $4^{\circ} \mathrm{C}$. Then, the supernatants were gathered and centrifuged at $12,000 \mathrm{xg}$ for $10 \mathrm{~min}$ at $4^{\circ} \mathrm{C}$. The serum samples were stored at $-80^{\circ} \mathrm{C}$ for analysis. Total exosome isolation reagent was used to isolate exosomes from serum samples following the manufacturer's protocol (Invitrogen). $0.2 \mathrm{~mL}$ of total exosome isolation reagent (Invitrogen) and $1 \mathrm{~mL}$ of serum were blended and incubated for $30 \mathrm{~min}$ at $4^{\circ} \mathrm{C}$. Then, exosomes was gathered and centrifuged at 10,000 $\times \mathrm{g}$ for $10 \mathrm{~min}$ at room temperature.

\section{Quantification of serum microRNA-132}

Total RNA was isolated using isothiocyanate-phenol/ chloroform extraction procedures. SYBR Premix Dimer Eraser kit (TaKaRa, Shiga, Japan) was used to perform real-time quantitative RTPCR (qRT-PCR) using ABI Prism 7900HT Detection System (Applied Biosystems, Foster City, CA).

\section{Anti-microRNA-132 plasmid transfection}

Anti-microRNA-132 plasmid:5' - CGCCAAUAUUUACGUGCUGCUA-3', the negative control: 5'-CAGUACUUUUGUGUAG UACAA-3'. Anti-microRNA-132 plasmid and negative control plasmid were structured by Sangon Biotech (Shanghai, China) and transfected into U87 cell using Lipofectamine 2000 (Invitrogen), according to the manufacturer's instructions.

\section{Cell culture and cell viability}

Human liver cancer MHCC97H cells were obtained from The First Hospital of Anhui Medical University and were cultured in DMEM culture medium (Gibco, Billings, MT, USA) containing 10\% fetal blood serum (HyClone-Thermo Scientific, Germany) supplemented with $100 \mathrm{U}$ of penicillin/mL, $100 \mathrm{mg}$ of streptomycin/ $\mathrm{mL}$ at $37^{\circ} \mathrm{C}$ under a humidified atmosphere of $5 \% \mathrm{CO}_{2}$. MHCC $97 \mathrm{H}$ cells-transfected was seeded onto 96-wellplate $\left(1 \times 10^{3}\right.$ cell/well $)$. Then, $10 \mu \mathrm{L}$ of thawed CCK- 8 solution (Wuhan Boshide Biotechnology Co., Ltd, Wuhan, China) was added to MHCC97H cells-transfected and incubated for 4 hours at $37^{\circ} \mathrm{C}$. Cell viability was read using the microplate reader (Thermo Fisher Scientific, Waltham, MA, USA) at $450 \mathrm{~nm} / 600 \mathrm{~nm}$.

\section{Cell apoptotic}

MHCC97H cells-transfected were analyzed by flow cytometry (Beckman Coulter Inc., Miami, FL, USA) using the annexin V-FITC/propidium iodide Apoptosis Detectionkit according tothe manufacturer's instructions (BestBio Biotechnology Co., Ltd, China). MHCC97H cells-transfected was seeded onto 6-well-plate (1-2 $\times 10^{6}$ cell/well) and washed by ice PBS. MHCC $97 \mathrm{H}$ cells was gathered and cultured with annexin V-FITC and propidium iodide on ice for $30 \mathrm{~min}$ in the dark. Cell apoptotic were measured using flow cytometry (Beckman Coulter Inc., Miami, FL, USA).

\section{Statistical analysis}

Data were expressed as the means \pm standard error (S.E.M.) and Kruskal-Wallis test were performed to determine the significance of the differences. A value of $<0.05$ was considered significant.

\section{Results}

\section{Characterization of participants}

There was no significant in age, sex, HBV status, liver cirrhosis and TNM staging in liver cancer and normal patients (Table I).

\section{Serum microRNA-132 expression in higher liver cancer patients}

In this study, there was no significant difference in age ( $\geq 60$ or $<60$ years), sex and HBsAg of low microRNA132 expression and high microRNA-132 expression (Table II). However, cases of liver cirrhosis of low microRNA-132 expression was higher than that of high microRNA-132 expression. The statistical analysis revealed that high level of serum microRNA-132 expression positively correlated with TNM staging.

Correlations of microRNA-132 expression and patient clinicopathologic characteristics

To determine the correlations of microRNA-132 expre- 


\begin{tabular}{|c|c|c|}
\hline \multicolumn{3}{|c|}{ Table I } \\
\hline \multicolumn{3}{|c|}{ Characterization of participants } \\
\hline & $\begin{array}{l}\text { Patient without } \\
\text { liver cancer } \\
(\mathrm{n}=24)\end{array}$ & $\begin{array}{c}\text { Liver cancer } \\
\text { group }(n=24)\end{array}$ \\
\hline Age (years) & $62.2 \pm 6.9$ & $63.1 \pm 7.2$ \\
\hline \multicolumn{3}{|l|}{ Sex } \\
\hline Female & 9 & 9 \\
\hline Male & 15 & 15 \\
\hline \multicolumn{3}{|l|}{ HBV status } \\
\hline Positive & 0 & 20 \\
\hline Negative & 24 & 4 \\
\hline \multicolumn{3}{|c|}{ Liver cirrhosis } \\
\hline Positive & 0 & 19 \\
\hline Negative & 24 & 5 \\
\hline \multicolumn{3}{|l|}{ TNM staging } \\
\hline I & & 7 \\
\hline II & & 6 \\
\hline III-IV & & 11 \\
\hline
\end{tabular}

ssion and patient clinicopathologic characteristics, microRNA-132 expression was measured by qRT-PCR. There was significant suppression in microRNA-132 expression of exosome and whose liver cancer cell, comparison with control group (Figure 1). Meanwhile, microRNA-132 expression of exosome cell was higher than that of whose cell in liver cancer cell or normal control group.
Mediation of microRNA-132 on cell growth of liver cancer cell

To determine whether down-regulation of microRNA132 played a role in the cell growth of liver cancer cell, we transfected MHCC97H cells with anti-microRNA132. As shown in Figure 2, transfection of antimicroRNA-132 inhibited cell growth of liver cancer cell, comparison with control group.

\section{Mediation of microRNA-132 on apoptotic of liver cancer cell}

We have showed down-regulation of microRNA-132 affect on apoptotic of liver cancer cell. These results indicated down-regulation of microRNA-132 activated apoptotic of liver cancer cell, comparison with control group (Figure 3).

\section{Discussion}

In our study, cases of liver cirrhosis of low microRNA132 expression were higher than that of high microRNA -132 expression. The statistical analysis revealed that high level of serum microRNA-132 expression positively correlated with TNM staging.

MiR-132 is highly conserved in evolution and possesses same arrays and structures in species like human beings, rats, mice and apes (Guo et al., 2014). It is positioned on chromosome 10 in rats while chromosome 11 and chromosome 17 are for mice and human beings, respectively (Maharshak et al., 2013). MiR-132 has tissue specificity and has high expressions in nerve-

\begin{tabular}{|c|c|c|c|c|}
\hline \multicolumn{5}{|c|}{ Table II } \\
\hline \multicolumn{5}{|c|}{ Serum microRNA-132 expression in higher HCC patients } \\
\hline Characteristics & $\mathrm{n}$ & Low $(\%)$ & High (\%) & P value \\
\hline \multicolumn{5}{|l|}{ Age (years) } \\
\hline$\geq 60$ & 17 & $10(58.8)$ & $7(41.2)$ & 0.971 \\
\hline$<60$ & 7 & $4(57.1)$ & $3(42.9)$ & \\
\hline \multicolumn{5}{|l|}{ Sex } \\
\hline Female & 9 & $6(66.7)$ & $3(33.3)$ & 0.588 \\
\hline Male & 15 & $9(60.0)$ & $6(40.0)$ & \\
\hline \multicolumn{5}{|l|}{ HBsAg } \\
\hline Positive & 20 & $11(55.0)$ & $9(45.0)$ & 0.361 \\
\hline Negative & 4 & $3(75.0)$ & $1(25.0)$ & \\
\hline \multicolumn{5}{|l|}{ Liver cirrhosis } \\
\hline Positive & 19 & $9(47.4)$ & $10(52.6)$ & 0.021 \\
\hline Negative & 5 & $5(100)$ & $0(0)$ & \\
\hline \multicolumn{5}{|l|}{ TNM staging } \\
\hline I & 7 & $6(85.7)$ & $1(14.3)$ & 0.001 \\
\hline II & 6 & $5(83.3)$ & $1(16.7)$ & \\
\hline III-IV & 11 & $3(27.3)$ & $8(72.7)$ & \\
\hline
\end{tabular}




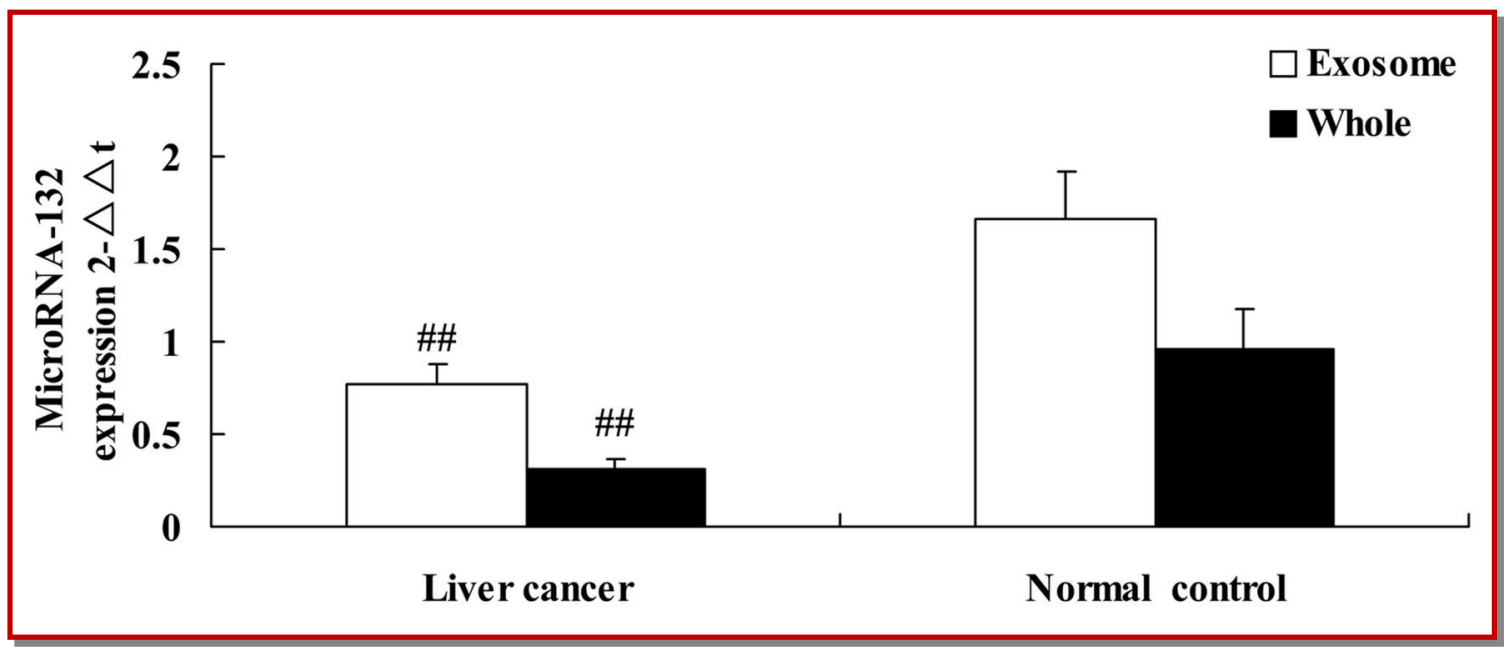

Figure 1: Correlations of microRNA-132 expression and patient clinicopathologic characteristics \#\# $\mathrm{p}<0.01$ compared with normal group

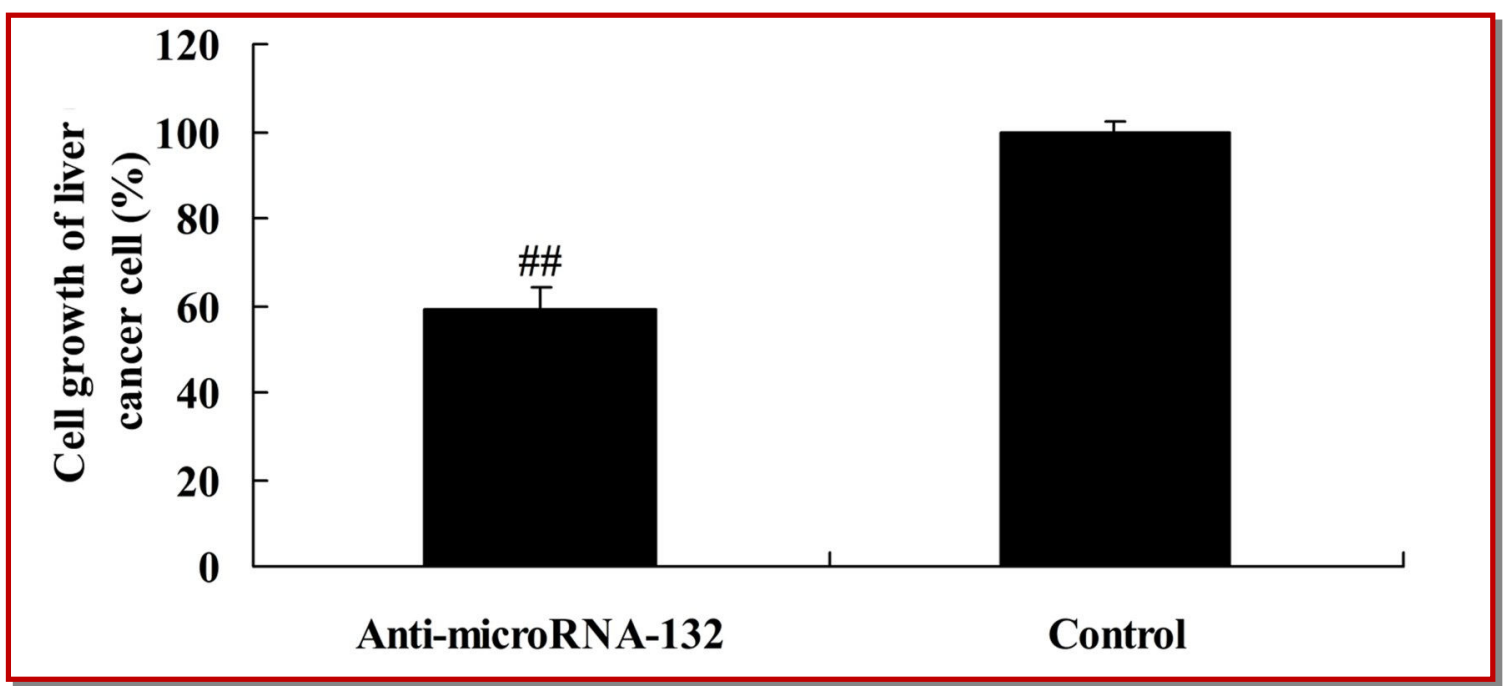

Figure 2: Mediation of microRNA-132 on cell growth of liver cancer cell; \#\# $\mathrm{p}<0.01$ compared with normal group

related tissues (Wang et al., 2013). It participates in axon growth, proliferation and differentiation of synapsis and formation of nerve tumors. It also takes part in regulating cancers, neurodegenerative diseases, schizophrenia and immunological diseases (Wanet et al., 2012). In present study, there was significant suppression in microRNA-132 expression of exosome and whose liver cancer cell. Meanwhile, microRNA-132 expression of exosome cell was higher than that of whose cell in liver cancer cell or normal control group.

Expression of miR-132 is regulated by promoters and play significant part in metastasis and colony formation of tumor cells (Wei et al., 2013). Studies showed that upstream stimulatory factor- 1 can increase expressions of miR-132 by incorporating with promoters of miR-132 (Kumarswamy et al., 2014). As a result, gene silencing of USF-1 can lead to down regulation of miR-132, then to avoid apoptosis of HepG2 cells under the conditions of oxygen-glucosede privation, which can be regarded as the therapeutic target (Wang et al., 2014). In carcinoma of prostate cells, methylation of CpG island could down regulate miR-132 which controls cell adhesion by directly acting on protein-heparinbinding epidermal growth factor and talin 2, thus prevent the metastasis of carcinoma of prostate (Wei et al., 2013). We found that the down-regulation of microRNA-132 could inhibit cell growth and activated apoptotic of liver cancer cell.

\section{Conclusion}

We observed cases liver cirrhosis of low microRNA-132 expression was higher than that of high microRNA-132 expression. There was significant suppression in microRNA-132 expression of exosome and whose liver cancer cell. Down-regulation of microRNA-132 could inhibit cell growth and activated apoptotic of liver cancer cell. Furthermore, our study indicated that 


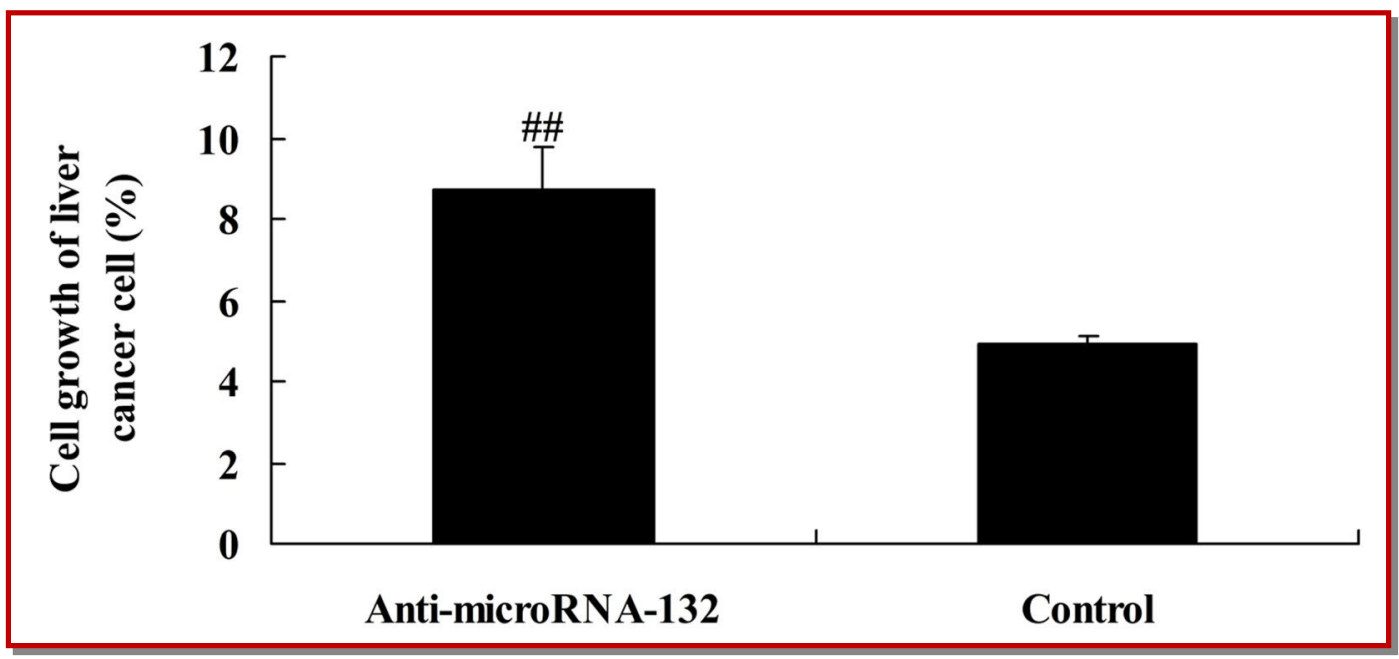

Figure 3: Mediation of microRNA-132 on apoptotic of liver cancer cell; $\# \#$ p $<0.01$ compared with normal group

microRNA-132 provides increased sensitivity of detection than normal patients. MicroRNA-132 may serve as a potential biomarker for treatment on liver cancer.

\section{Ethical Issue}

The study was approved by the Institutional Review Board of Hospital Ethics Committee. Written consents were obtained from all subjects prior to the recruitment.

\section{References}

Allam N, Al Saghier M, El Sheikh Y, Al Sofayan M, Khalaf H, Al Sebayel M, Helmy A, Kamel Y, Aljedai A, Abdel-Dayem H, Kenetman NM, Al Saghier A, Al Hamoudi W, Abdo AA. Clinical outcomes for Saudi and Egyptian patients receiving deceased donor liver transplantation in China. Am J Transplant. 2010; 10: 1834-41.

Behe M, Becker W, Gotthardt M, Angerstein C, Behr TM. Improved kinetic stability of DTPA- dGlu as compared with conventional monofunctional DTPA in chelating indium and yttrium: Preclinical and initial clinical evaluation of radiometal labelled minigastrin derivatives. Eur J Nucl Med Mol Imaging. 2003; 30: 1140-46.

Gonzalez-Vacarezza N, Abad-Santos F, Carcas-Sansuan A, Dorado P, Penas-Lledo E, Estevez-Carrizo F, Llerena A. Use of pharmacogenetics in bioequivalence studies to reduce sample size: An example with mirtazapine and CYP2D6. Pharmacogenomics J. 2013; 13: 452-55.

Guo J, Wang H, Wang Q, Chen Y, Chen S. Expression of pCREB and activity-dependent miR-132 in temporal lobe epilepsy. Int J Clin Exp Med. 2014; 7: 1297-306.

Kim DS, Marsillach J, Furlong CE, Jarvik GP. Pharmacogenetics of paraoxonase activity: Elucidating the role of highdensity lipoprotein in disease. Pharmacogenomics 2013; 14: 1495-515.
Kumarswamy R, Volkmann I, Beermann J, Napp LC, Jabs O, Bhayadia R, Melk A, Ucar A, Chowdhury K, Lorenzen JM, Gupta SK, Batkai S, Thum T. Vascular importance of the miR -212/132 cluster. Eur Heart J. 2014; 35: 3224-31.

Lam MP, Yeung CK, Cheung BM. Pharmacogenetics of allopurinol--making an old drug safer. J Clin Pharmacol. 2013; 53: 675-79.

Li YH, Huang X, Wang Y, Fan R, Zhang HM, Ren P, Chen Y, Zhou HH, Liu ZQ, Liang YZ, Lu HM. Pharmacokinetic comparison of the vasorelaxant compound ferulic acid following the administration of guanxin II to healthy volunteers and patients with angina pectoris. Exp Ther Med. 2013; 6: 1283-89.

Maharshak N, Shenhar-Tsarfaty S, Aroyo N, Orpaz N, Guberman I, Canaani J, Halpern Z, Dotan I, Berliner S, Soreq H. MicroRNA-132 modulates cholinergic signaling and inflammation in human inflammatory bowel disease. Inflamm Bowel Dis. 2013; 19: 1346-53.

Outwater EK. Imaging of the liver for hepatocellular cancer. Cancer Control. 2010; 17: 72-82.

Tang ZY. Hepatocellular carcinoma: Cause, treatment and metastasis. World J Gastroenterol. 2001; 7: 445-54.

Toffanin S, Alsinet C, Cornella H, Sia D, Llovet JM. microRNAs and the MYC network: A major piece in the puzzle of liver cancer. Gastroenterology 2011; 140: 2138-40.

Vasku V, Vasku A, Vasku JB. Pharmacogenetic contribution of leptin gene polymorphism in cutaneous T-cell lymphoma. Int J Clin Exp Pathol. 2009; 2: 163-68.

Wanet A, Tacheny A, Arnould T, Renard P. miR-212/132 expression and functions: Within and beyond the neuronal compartment. Nucleic Acids Res. 2012; 40: 4742-53.

Wang R, Liang H, Li H, Dou H, Zhang M, Baobuhe, Du Z, Gao M, Wang R. USF-1 inhibition protects against oxygen-andglucose-deprivation-induced apoptosis via the downregulation of miR-132 in HepG2 cells. Biochem Biophys Res Commun. 2014; 446: 1053-59.

Wang RY, Phang RZ, Hsu PH, Wang WH, Huang HT, Liu IY. 
In vivo knockdown of hippocampal miR-132 expression impairs memory acquisition of trace fear conditioning. Hippocampus 2013; 23: 625-33.

Wei X, Tan C, Tang C, Ren G, Xiang T, Qiu Z, Liu R, Wu Z. Epigenetic repression of miR-132 expression by the hepatitis $B$ virus $x$ protein in hepatitis $B$ virus-related hepatocellular carcinoma. Cell Signal. 2013; 25: 1037-43.

Wolosz D, Walczak A, Wilczynski GM, Szparecki G, Wilczek E, Gornicka B. Deleted in liver cancer 1 expression and localization in hepatocellular carcinoma tissue sections. Oncol Lett. 2014; 8: 785-88.

Xie X, Yao M, Chen X, Lu W, Lv Q, Wang K, Zhang L, Lu F.
Reduced red blood cell count predicts poor survival after surgery in patients with primary liver cancer. Medicine (Baltimore). 2015; 94: e577.

Zhang L, Huang D, Wang Q, Shen D, Wang Y, Chen B, Zhang J, Gai L. MiR-132 inhibits expression of SIRT1 and induces pro-inflammatory processes of vascular endothelial inflammation through blockade of the SREBP-1c metabolic pathway. Cardiovasc Drugs Ther. 2014a; 28: 303-11.

Zhang Y, Zhang WL, Huang DS, Hong L, Wang YZ, Zhu X, $\mathrm{Hu} \mathrm{HM}$, Zhang PW, Yi Y, Han T. Clinical effectiveness of multimodality treatment on advanced pediatric hepatoblastoma. Eur Rev Med Pharmacol Sci. 2014b; 18, 1018-26.

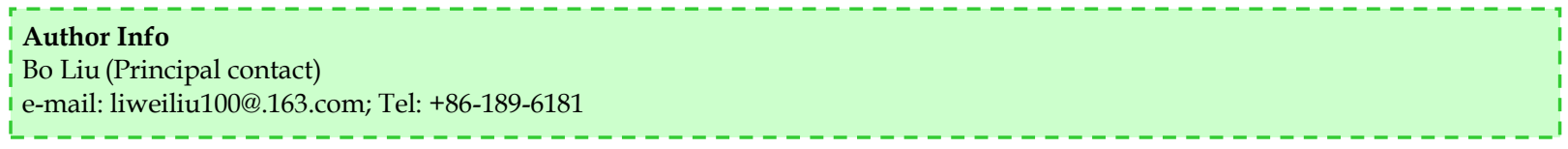

